\title{
La familia ensamblada y su inclusión en el Derecho Sucesorio Agrario: problemática jurídica
}

\section{The Assembled Family and their Inclusion in Agrarian Inheritance Law: Legal Problem}

Gretcher Lamas Bertrán* https://orcid.org/0000-0001-8068-8615 Mary Dennis Londres Osorio**https://orcid.org/0000-0001-5679-5111

Dayamis Ramírez Thomas**^https://orcid.org/0000-0001-6008-8508

http://dx.doi.org/10.21503/lex.v18i25.2108

*Profesora de Derecho Notarial, Derecho Internacional Privado y Derecho de Sucesiones en el Departamento de Derecho de la Universidad de Guantánamo, Cuba.

Correo electrónico: gretcherlb@cug.co.cu

**Profesora de Derecho Internacional Público y Derecho Romano en el Departamento de Derecho de la Universidad de Guantánamo, Cuba.

Correo electrónico: maryd@cug.co.cu

*** Profesora principal de Derecho Civil Parte General y Bioética y Derecho en el Departamento de Derecho de la Universidad de Guantánamo, Cuba.

Correo electrónico: dayamisrt@cug.co.cu

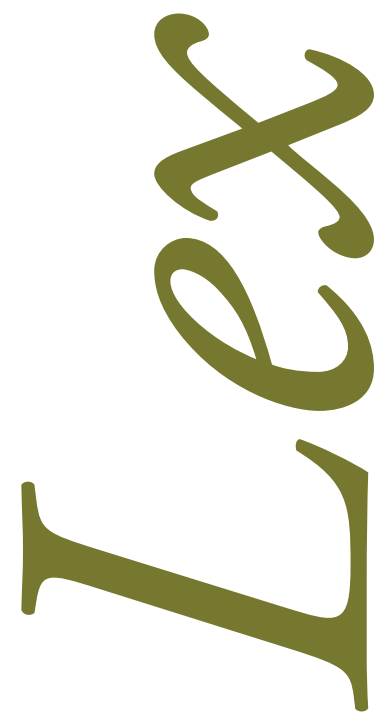




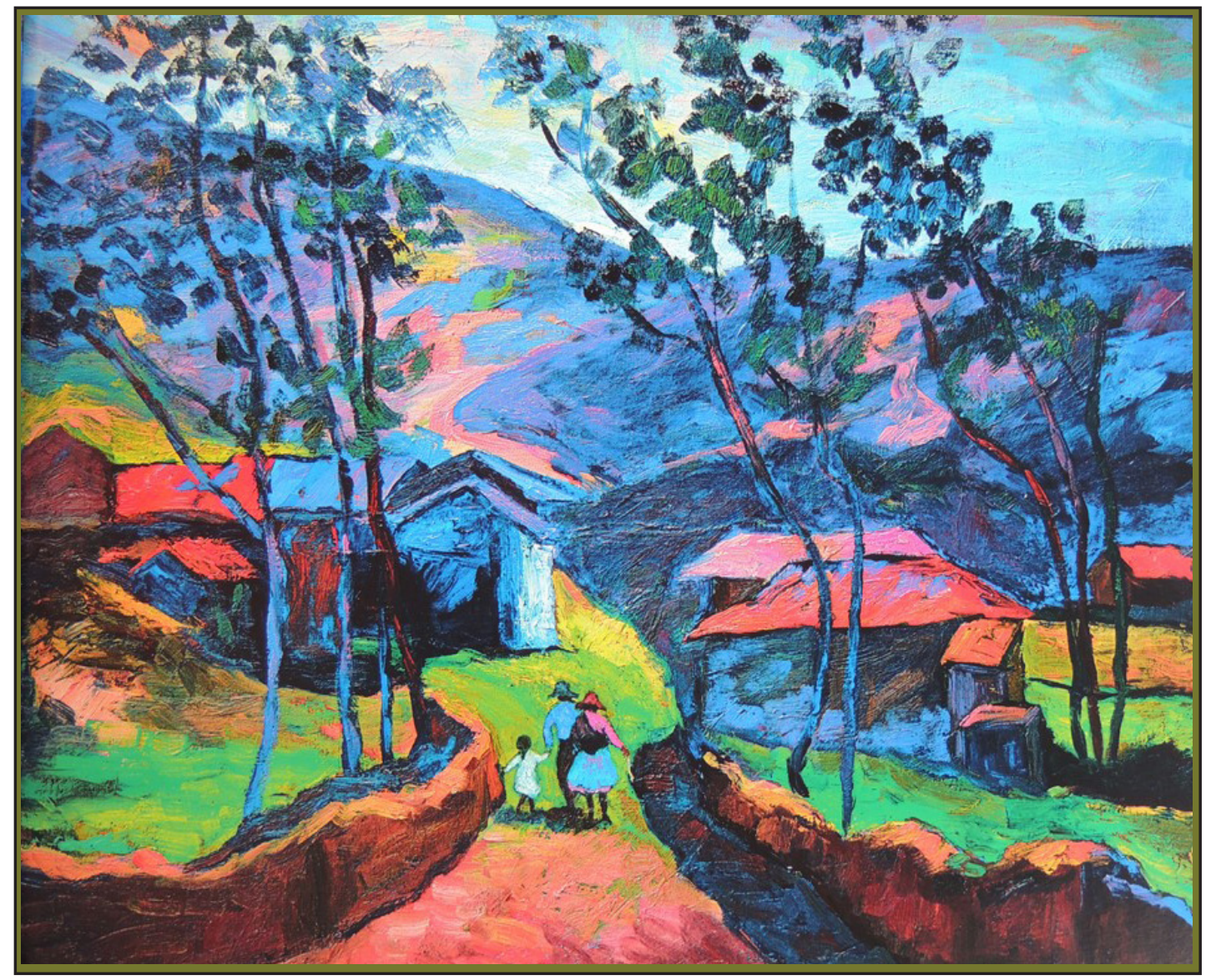

Pueblo de Cal y Canto. Óleo sobre lienzo 65 x $81 \mathrm{~cm}$. Sonia Estrada Melgarejo (pintora peruana, Ancash) 


\title{
RESUMEN
}

El presente artículo pretende reconocer la plenitud del goce de los derechos sucesorios de la familia ensamblada en materia agraria, pues no es secreto alguno que existen evidencias de vacíos e insuficiencias en los ordenamientos jurídicos tanto latinoamericanos como europeos vinculados a la familia, así como a la investigación en cuanto a la relación de esta institución con el Derecho Agrario en materia sucesoria. En nuestro país, rige una normativa familiar que se circunscribe estrictamente a la familia nuclear, excluyendo nuevos modelos familiares que constituyen una realidad latente en nuestra sociedad y que se encuentran completamente desprotegidos en materia normativa, tal es el caso de la familia ensamblada o reconstituida. Es por ello, que con el presente trabajo se pretende buscar vías de solución a fin de que el ordenamiento jurídico cubano brinde una protección eficaz a los miembros de estas familias, a fin de lograr un equilibrio entre la materia sucesoria agraria y el progreso social que ha presentado en los últimos ańos la institución familiar.

Palabras clave: familia ensamblada, derecho agrario, materia sucesoria.

\begin{abstract}
This article aims to recognize the full enjoyment of the inheritance rights of the family assembled in agrarian matters, since it is no secret that there is evidence of gaps and inadequacies in both Latin American and European legal systems related to the family, as well as to the investigation as to the relation of this institution with the Agrarian Law in inheritance matters. In our country, there is a family regulation that strictly limits the nuclear family, excluding new family models that constitute a latent reality in our society and that are completely unprotected in normative matters, such is the case of the assembled or reconstituted family. That is why, with the present work it is tried to look for ways of solution so that the Cuban legal system provides an effective protection to the members of these families, in order to achieve a balance between the agrarian succession matter and the social progress that has presented in recent years the family institution.
\end{abstract}

Key words: family assembled, agricultural law, inheritance 


\section{INTRODUCCIÓN}

El Derecho Agrario constituye la rama del Derecho que regula las dificultades que puedan presentarse sobre la tenencia de la tierra y la actividad agropecuaria que se realiza sobre ella. Es un derecho que carga sobre sus hombros la responsabilidad de solucionar los conflictos y demandas de cualquier índole referidas a la producción agraria; es por tanto, un derecho multifacético con peculiaridades propias pero necesitado aún de perfeccionamiento.

Cuba no escapa de esta realidad y en las actuales circunstancias de actualización del modelo económico, el Derecho Agrario se revela como necesario para buscar soluciones a los problemas cada vez más complejos de la agricultura, que inciden en el desarrollo rural del país; pero no solo respuestas económicas y políticas, sino también aquellas que trascienden a lo más intrínseco de la sociedad y afectan directamente a la familia, tal es el caso de la sucesión en materia agraria.

La influencia de varios factores socioeconómicos en los últimos años ha proporcionado la aparición de nuevas categorías dentro del ámbito jurídico donde las relaciones familiares no han quedado exentas de ser afectadas por ellos. Al respecto se han suscitado numerosos debates a partir de que la diversificación familiar presente en la sociedad ha dejado rezagada a la norma jurídica al no satisfacer todas las necesidades que van surgiendo. En la arista internacional existen algunos autores que han tratado el tema en cuestión ${ }^{1}$; sin embargo en la normativa patria han sido escasas las investigaciones referidas a Derecho Agrario en materia familiar y sucesoria ${ }^{2}$, rigiendo hoy en Cuba un orden jurídico

1. Vgr. En la arista internacional de la bibliografía estudiada, entre los autores que más se acercan al tema objeto de esta investigación encontramos a: Mérida, Venezuela. Belquis Cecilia Sáez Nieto, (2013) "Derecho Agrario", La sucesión agraria en Panamá. Luis Agustín Hinojos Villalobos, (2003), La concubina ante la sucesión legítima agraria. F. Ramón Fernández, (2016), "La sucesión de la empresa familiar agraria valenciana", en El nuevo Derecho agrario, coordinado por L. Abreu Barroso, E. Maniglia, y Gunsen De Miranda. Ricardo Zeledón Zeledón, (2011) El Derecho Agrario Contemporáneo, San José, Costa Rica.

2. Vgr. En la arista nacional referido al tema tratado podemos citar algunas investigaciones, entre las más cercanas al tema encontramos: Maritza McComack Béquer, (2003), "La propiedad de los agricultores pequeños. Su transmisión por causa de muerte, como instituto del Derecho Agrario" (tesis Doctoral en Ciencias Jurídicas, Inédita), La Habana, Cuba. Sandra Fernández Peña, (2007), "El procedimiento para la herencia de la tierra y demás bienes agropecuarios 
en materia de familia que solo alcanza a la familia nuclear, quedando rezagado respecto a nuevos modelo familiares que necesitan hoy ser protegidos jurídicamente, tal es el caso de la familia ensamblada o reconstituida ${ }^{3}$ tan presente en cualquier sociedad hoy en día.

\section{ALGUNAS PINCELADAS SOBRE LA FORMA DE SUCEDER LA TIERRA A LO LARGO DE LA HISTORIA}

El orden sucesorio agrario se ha caracterizado por constituir uno de los temas más enumerados a nivel mundial, dado el papel significativo que ha representado la tierra desde tiempos antiguos. El Código de Hammurabi, que data del año 1728 a.C, en el tema que nos ocupa planteaba que para el caso de un hombre que diera en propiedad un campo, una huerta o un objeto a su esposa, después de fallecida esta, sus hijos no tenían derecho, solo heredaba a la madre aquel que fuera su preferido. Por otro lado si un hombre regalaba un campo, una huerta o una casa a su heredero predilecto, después de fallecido, el hijo se quedaba con la donación que le había hecho su padre además de lo que le correspondía por herencia.

En el Derecho Romano antiguo, solo heredaba el primogénito, preferentemente el hijo varón. Por su parte en el Derecho Germano o de Costumbres de París y el Norte de Francia, los hijos heredaban por partes iguales, generalmente solo los hijos varones. No hay derecho de primogenitura a diferencia del Derecho Romano.

En el Derecho Feudal, no solo se heredaba la tierra, sino los títulos de nobleza, que iban adjuntos a ella. Heredaba solamente un hijo primogénito, casi siempre varón, incluso en el caso de que hubiera hijas mujeres se le dejaba la herencia al hijo mayor entre los varones, pues estas, generalmente no heredaban al no transmitir la nobleza a sus descendientes.

Fue solo hacia el año 1000 d.C cuando el término feudo comenzó a emplearse en sustitución de beneficio. A partir de ese momento se aceptaba de forma unánime que las tierras entregadas al vasallo fueran hereditarias, con tal de que el heredero que las recibiera fuera grato al señor y pagara un im-

del pequeño agricultor fallecido. Comportamiento en el municipio de Holguín" (tesis de Especialidad en Asesoría Jurídica), Universidad de Holguín, Cuba. José Julián Figueras, (2006), “La Transmisión de la Tierra en Cuba” (tesis de Especialidad en Asesoría Jurídica) Universidad de Guantánamo, Cuba. Antonio Ramírez Columbié, (2005) "Hacia un procedimiento agrario común" (tesis de Especialidad en Derecho Civil y Familia), Universidad de Oriente, Santiago de Cuba, Cuba. Migdalia Ramírez Peña, (2005) "Instituciones del Derecho de Familia en el Marco de los Conflictos sucesorios agrarios" (tesis de Especialidad en Derecho Civil y Familia) Universidad de Oriente, Santiago de Cuba, Cuba. Irliet Matos Rey, Alexey Berenguer Sánchez, y Juan Carlos Mendoza Pérez, (2017), Los retos del Decreto Ley 125/91 ante las limitaciones de interés privado en el ejercicio del Derecho de Propiedad de los agricultores pequeños en Cuba.

3. Familia ensamblada o reconstituida: son aquellas familias que se forman entre personas que han sido parte de una familia anterior y cuyo matrimonio ha sido extinguido por fallecimiento o divorcio de uno de los cónyuges, al igual que pudo haber existido una unión de hecho anterior de la que se procrearon hijos. Extraído de María Silvia Dameno, s.f. Familias Ensambladas.pdf 
puesto de herencia llamado socorro. Si un vasallo moría y dejaba a un heredero mayor de edad y buen caballero, el señor no tenía por qué objetar su sucesión; sin embargo, si el hijo era menor de edad o si el heredero era mujer, el señor podía asumir el control del feudo hasta que el heredero alcanzara la mayoría de edad o la heredera se casara con un hombre que tuviera su aprobación. La viuda de un vasallo tenía derecho a una pensión de por vida sobre el feudo de su marido, lo que también llevaba a provocar el interés del señor porque la viuda contrajera nuevas nupcias. En el caso de muerte de un vasallo sin sucesores directos, la relación de los herederos con el señor variaban, los hermanos fueron normalmente aceptados como herederos, no así los primos.

En la Revolución Francesa iniciada el 14 de julio de 1789 la repartición de las sucesiones implicaba la distribución de la tierra y debía estar situada dentro de su nueva visión de la propiedad. Con la promulgación del Código de Napoleón o Código Civil de Francia aprobado por Ley el 21 de marzo de 1804, muchas de las ideas de la Revolución Francesa son reexaminadas y corregidas por el nuevo sector gobernante de la alta burguesía. Respecto a la sucesión de bienes, establece la igualdad de reparto sucesorio entre los herederos legítimos, en su defecto, a los hijos naturales, después a la esposa sobreviviente y de no existir esta, los bienes pasan a la República. Establece la posibilidad de disponer mediante testamento de todos sus bienes, incluyendo la tierra ${ }^{4}$, o parte de ellos. Plantea además en su artículo 1064 que "el ganado y utensilios para trabajar las tierras se reputarán comprendidos en las donaciones entre vivos o testamentarias de dichas tierras; y el obligado a la transmisión estará solamente obligado a hacerlos tasar y estimar, para entregar un valor igual en el momento de la transmisión".

Hasta este momento, la sucesión mortis causa de la propiedad agraria se considera una adquisición derivativa, y no fue hasta 1917 en México, donde por primera vez se hizo una distinción entre la propiedad civil y la propiedad agraria. Es luego de la década del 40 del siglo XX cuando en Europa se observan mayores avances en la instauración de instituciones agrarias independientes, como una vía para refrendar las transformaciones socioeconómicas introducidas en el sector agrario concluida la Segunda Guerra Mundial en consonancia con el interés de desarrollo de las relaciones capitalistas en el ámbito rural. Así en Italia por la Ley 1094 de 4 de agosto de 1948, modificada por la Ley 392 de 3 de junio de 1950 y más tarde por la Ley 203 de 1982, se crearon las "Sezioni Specializzate Agraria dei Tribunali", con competencia particularizada en el conocimiento de conflictos derivados de contratos de arrendamiento entre propietarios y aparceros.

En la década del 50 en Alemania, se crearon los "Landwirtschaftsgerichte", que constituyeron nuevos órganos judiciales a los que se atribuyeron competencias para conocer de reclamaciones y controversias sobre contratos de arrendamiento, expropiación y transmisión de tierras agrarias y forestales. Pero en el caso de Europa cabe observar como regla general que al lado de los nuevos órganos jurisdiccionales especializados que se crearon, no se articula una tendencia hacia la institución de procesos especiales agrarios.

4. De los artículos 815 al 842 se plasma todo lo referente a la división y partición de la producción agrícola.. 
En los países de Europa del Este, concluida la Segunda Guerra Mundial, la promulgación de Leyes de Reforma Agraria, en el marco de las revoluciones sociales conducentes a la instauración del régimen socialista en Polonia, Rumania, Hungría y Checoslovaquia, Bulgaria, Yugoslavia, Albania y Alemania Oriental no trajo como consecuencia inmediata la conformación de un Derecho Agrario autónomo desde el punto de vista legislativo y jurisdiccional, apreciándose como regularidad, que en estos países al igual que en la extinta Unión de Repúblicas Socialistas Soviéticas (URSS), las relaciones agrarias se mantuvieron sometidas a las normas de Derecho Civil y de Derecho Administrativo, y aunque didáctica y científicamente el Derecho Agrario alcanzara cierto grado de autonomía en algunos casos, no se produjo allí la creación de instituciones jurisdiccionales y procesales autónomas en materia agraria, lo cual estuvo determinado por diversas peculiaridades históricas y políticas.

En el caso específico de la extinta URSS, hubo controversias al referirse al tema de un Derecho Agrario independiente, pues muchos autores al enumerar las ramas del Derecho Soviético no incluyeron al Derecho Agrario, sino al Derecho Koljosiano o al Derecho de las Cooperativas. Ello es coherente con el hecho de que allí la propiedad de la tierra casi en su totalidad había pasado al fondo estatal y que los tenedores tanto individuales como las cooperativas ocupaban las tierras en condición de usufructuarios. En consonancia con ello la legislación agraria soviética y de las Repúblicas Federadas del 13 de diciembre de 1968 había establecido en su artículo 49 que: "Los litigios agrarios entre koljoses $^{5}$, sovjoses, empresas, cooperativas y ciudadanos se resolverán por el Consejo de Ministros de las Repúblicas Federadas y por el Comité Ejecutivo de los Soviets Locales”. ${ }^{6}$

Actualmente la terminología de herencia de la tierra ha sido utilizada por varios autores como sucesión agraria. Saes Nieto ${ }^{7}$ la conceptualiza "como la transmisión de los derechos activos y pasivos utilizados para la realización de una actividad agraria por el causante a la persona que sobrevive, a la cual la ley o el testador llama para recibirla"; mientras Villalobos (s.ff) define como sucesión legitima agraria: "La facultad que la Ley Agraria concede a una persona para heredar los derechos agrarios del titular de estos (ejidatario o comunero) una vez que ha fallecido, entendida en razón del grado de parentesco o a falta de este, de la dependencia económica guardada con el de cujus de acuerdo con la lista de llamamientos o grado de preferencia establecida por ella" ${ }^{\prime}$

Lo cierto es que la sucesión agraria ha sido totalmente opuesta a la sucesión común por ser catalogada como propia, autónoma y auténtica desde el punto de vista normativo y jurisdiccional. Sumado

5. Koljoses: Nombre que recibían granjas colectivas en la Unión Soviética.

6. Sovjoses: Neologismo ruso utilizado para denominar a las explotaciones agrícolas que en la extinta Unión Soviética no tenían carácter cooperativo, sino que dependían directamente del Estado.

7. Saes Nieto. B.C, Derecho Agrario. La sucesión agraria en Panamá, 2013, 8, acceso el 15 de noviembre de 2018 , estufamil.blogspot.com/2013/06/sucesion-agraria-n-ombre.html.

8. Luis Agustín Hinojos Villalobos, "La concubina ante la sucesión legítima agraria", Estudios Agrarios, (s.f), p. 104-115, acceso el 25 de octubre de 2019, www.pa.gob.mx.publica.pdf. 
a ello, el Derecho Agrario hereditario no ha seguido un mismo modelo en los diferentes continentes, ni siquiera en los países miembros de cada uno, pues cada nación adecua la herencia en materia agraria a su propia realidad. Así, por ejemplo, en la Unión Africana se promulgó una Ley en fecha Primero de Julio de 2002, que recoge entre sus preceptos que ante la presencia de un cónyuge superviviente e hijos legítimos, hay dos opciones: el cónyuge superviviente puede heredar un cuarto de la plena propiedad y los hijos los tres cuartos restantes, o toda la propiedad en usufructo, pero los hijos mantienen la nuda propiedad (pueden enajenarla). Si los hijos no son todos del matrimonio, entonces el cónyuge superviviente no tiene opción: recibe solo un cuarto de la plena propiedad. Si no hay hijos, el cónyuge superviviente no hereda instintivamente; debe compartir en las mismas proporciones ( $1 / 4$ o usufructo del total) con los parientes colaterales. En ausencia de un cónyuge sobreviviente, y sin descendientes, los bienes, pasan a los ascendientes y colaterales y, por último, al Estado.

Los cambios acaecidos en cuanto a la regulación del Derecho Agrario, incluido el derecho sucesorio agrario, se hicieron extensivos a Latinoamérica con la existencia y aprobación de códigos agrarios en países como Nicaragua, México, Venezuela, República Dominicana, Panamá y Cuba, donde en la primera mitad del siglo XX se suscitaron varias normativas en este orden hasta las actuales tras el triunfo revolucionario del Primero de enero de 1959.

Por todo lo antes expuesto se puede asegurar que el derecho sucesorio agrario en las diferentes etapas de su desarrollo se vio enmarcado en las costumbres y condiciones concretas de cada momento histórico, siendo la familia, vista también según el momento histórico concreto, principal protagonista en cada una de estas etapas.

\section{LA FAMILIA ENSAMBLADA EN EL DERECHO SUCESORIO AGRARIO}

La evolución social y jurídica de la familia en buena parte de la historia de la humanidad, ha mostrado la primacía dada al modelo de la familia nuclear, y como una consecuencia de ello en la mayoría de las sociedades occidentales los nexos de parentesco quedan reducidos a un número limitado de parientes cercanos, siendo este el patrón reflejado por el Derecho Civil y Familia en torno a los alcances del concepto de familia y del derecho a la herencia. Sobre esta concepción que se fue imponiendo se han formulado importantes reservas como que la familia no debe ser reducida al conjunto constituido por los cónyuges y los hijos aunque sobre ellos se encuentre el mayor peso de la política familiar, sino que las relaciones interdependientes y recíprocas se extienden por imperio de la ley hacia todas aquellas personas que reconocen entre sí generaciones biológicas antecedentes o acontecimientos consecuentes que les son comunes. Así hoy podríamos referirnos a familias homoparentales, ampliadas, monoparentales y ensambladas ${ }^{9}$, además de la típica familia nuclear.

9. Familia ensamblada, reconstituida, reconstruida, reorganizada, recompuesta, amalgamada, afín, mixta o familiastra, son todas las denominaciones con las que se designa en idioma español al tipo de organización familiar que se constituye a partir del segundo o ulterior matrimonio o unión de hecho de un progenitor o de ambos. 
Resulta prudente advertir sobre la imposibilidad de asignarle a alguna de las clasificaciones de la familia el carácter de estereotipo para identificar a las familias rurales, por muy diversas circunstancias como los tipos diferentes de actividad agropecuaria, el tamaño de las propiedades, las tradiciones, costumbres, el derecho a la tierra, entendido por Rolando Pavó como "el derecho subjetivo, a ser sujeto de la propiedad individual o colectiva sobre la tierra, a obtener su adjudicación en concepto de propietario, a ser sujeto del usufructo y a ejercer cuantas acciones sean pertinentes para obtenerla y conservarla" 10 y otros factores, que han marcado la diferencia entre el modo de vida en regiones distintas, dado que además "estas clasificaciones de la familia en monoparentales, extensas y compuestas, pueden resultar «inflexibles y limitadas»"11

Lo mismo ocurre cuando se habla de Derecho Sucesorio Agrario en las modalidades familiares que no incluyen la familia nuclear, dígase, por ejemplo, la familia ensamblada. Es conocido que muchos hombres de campo escogen a su compañera de vida y con darla a conocer en su comunidad sienten satisfecho todo afán de legalidad, visualizándose entonces una nupcialidad muy baja en el medio rural, predominando históricamente la consensualidad como patrón de formación de la familia. Asimismo, suele llamar y tratar como hijos a algunos sobrinos, a sus nietos y a los hijos de su esposa, cuando los ha criado desde pequeńos, no reconociendo ninguna diferencia entre estos y sus hijos legítimos, soliendo expresar además que cuando fallezca desea que todos sus hijos y su mujer sean dueños por igual de todo lo suyo; es por ello que para estas autoras la familia ensamblada en el ámbito del Derecho Agrario es aquella que sin tener necesariamente vínculos consanguíneos está compuesta por las personas o integrantes que han sido parte de una familia anterior y deciden unirse para formar un nuevo núcleo familiar por motivos de afecto amor, amistad y propósitos comunes cuyas relaciones se desarrollan en el ámbito rural agrario: ya no será solo aquel hijo, esposa(a), nieto, sino también aquel ahijada(o), aquel vecino o conocido o aquel hijo que no es adoptivo, pero tienen en común que realizan una actividad agropecuaria; por tanto a los efectos de la ley también tienen que ser reconocidos como familia al momento de la adjudicación de la herencia del agricultor pequeño, no solo por esos vínculos de cariño, amor y amistad, sino también porque llevan adelante el negocio familiar que en este caso consiste en la labor agrícola.

Resulta obvio entonces que esta noción de familia entre en contradicción con lo que ha sido establecido por las normas jurídicas civiles tradicionales dando comienzo a un conflicto que resquebrajará la unidad de esa familia, y trascenderá a su comunidad rural que defenderá el derecho de unos o de otros al ver reflejada su propia realidad, afectándose el cumplimiento de la función económica y social de la familia y de la finca. Existe pues un desencuentro entre los conceptos de familia desde el punto de vista sociológico y jurídico, que se manifiesta en una reducción del tipo de parientes que de acuerdo

10. Rolando Pavó Acosta, La Justicia Agraria y sus Desafios, (La Habana, Cuba: Unijuris, 2012), 162.

11 M.E. Espocendra Amor, "Las relaciones de parentesco como forma de vínculo social" (tesis de Doctorado en Ciencias Sociológicas, Universidad de La Habana, Cuba, 2000), 93. 
con su grado de parentesco se les concede derecho a heredar, eso sin mencionar que en el campo ha sido frecuente que los padres no reconozcan legalmente a sus hijos o al presentar errores en las certificaciones que prueban el parentesco, el trámite se vuelva tan engorroso que casi nunca llegue a feliz término. Además a ello ha de sumarse que en el trabajo de la tierra muchas veces los parientes afines juegan un papel protagónico, y la norma jurídica actual no protege esta realidad rural.

Todas estas realidades contradictorias suelen dar lugar a inseguridad jurídica, demoras indebidas y decisiones injustas en los procedimientos de herencia de tierra, generando afectaciones a la estabilidad en la situación posesoria en la familia, que constituye uno de los presupuestos insoslayables para alcanzar el desarrollo rural. Tales circunstancias transitan en los espacios de la familia, conformando toda una cultura sobre la adaptación y disfrute de la vida en el campo. Estudios sociológicos han demostrado que en las zonas rurales el hogar desempeña un rol mucho más sistemático y relevante en la educación de los niños y adolescentes que el que puede corresponderle en las ciudades. Por ello se vuelve indispensable la revisión del derecho sucesorio agrario buscando una mejor protección de los derechos subjetivos de los habitantes del campo, tanto en materia sustantiva, es decir, de los requisitos para heredar; como en el orden procesal, o sea, el ejercicio de las acciones jurídicas ante los órganos que correspondan para lograr la realización de la justicia agraria mediante leyes que resulten más acordes a las características y roles de la familia rural y de las percepciones que sobre esta institución poseen los hombres del campo.

En efecto, a pesar de resultar evidente el fenómeno de la ramificación de la familia, su tratamiento jurídico por lo general no está en consonancia con ello, pues no siempre fundamenta y justifica suficientemente las razones acerca de la reducción de los límites en los grados de parentesco hasta el cual se concibe el derecho a heredarse, generando tales limitaciones tensiones y conflictos innecesarios entre los parientes ya sean consanguíneos o afines, debilitando con ello el sentimiento de identidad familiar, produciendo afectaciones en el desarrollo de las actividades económicas, derivando en falta de sostenibilidad de los modelos de desarrollo basados en la economía familiar.

\section{LA FAMILIA ENSAMBLADA EN LA LEGISLACIÓN AGRARIA CUBANA. VALORACIÓN CRÍTICA}

La puesta en vigor en Cuba del Decreto - Ley No.125 de fecha 30 de enero de 1991: "Régimen de Posesión, Propiedad y Herencia de la Tierra y Bienes Agropecuarios” y su Reglamento la Resolución 24/91, dispuso que todos los trámites para el reconocimiento de derechos hereditarios sobre tierras de propiedad individual y para la adjudicación de las mismas se realizaran directamente ante los funcionarios del Ministerio de la Agricultura, eliminándose así la necesidad de intervención judicial o notarial y, al mismo tiempo, enfatizó el criterio de que las reclamaciones y conflictos sobre propiedad y posesión de finca rústica se extrajeran de la competencia judicial y se sometieran exclusivamente a la decisión del Ministerio de la Agricultura. 
El citado Decreto - Ley trajo consigo la implementación de nuevos cambios que de cierta manera fueron más ventajosos respecto a su precedente legislativo ${ }^{12}$, pero no se imaginó que el mismo también contemplara una serie de deficiencias que afectan actualmente a los agricultores pequeños, como las diferentes instancias para la solución de los litigios, de manera que, si bien era necesaria la transformación de su precedente legislativo, muchos elementos contenidos en las normas actuales deben modificarse; atendiendo a las condiciones concretas y al futuro de las relaciones productivas agrícolas y familiares.

La aplicación del actual Decreto Ley ha sido objeto de disímiles críticas, tanto subjetivas como objetivas, producto de las diversas lagunas presentes en el mismo. En la práctica se hace casi imposible conjugar lo preceptuado en la legislación agraria, en cuestiones de herencia, con los artículos del Código Civil dado su carácter supletorio, por ser diametralmente opuestos. De ahí la necesidad regular la sucesión agraria de forma completa, con todas las figuras jurídicas necesarias prevista en la legislación sucesoria común.

En cuanto a la noción de familia y la concepción jurídica de la herencia de los bienes agropecuarios, merece una mirada con detenimiento el artículo 18 del mencionado Decreto Ley que regula: "tendrán derecho a heredar la tierra y bienes agropecuarios que hayan sido propiedad y estado en posesión de un agricultor pequeño fallecido, y a su adjudicación en proporciones iguales, sus hijos, padres, hermanos y el cónyuge sobreviviente, siempre que hayan trabajado la tierra en forma permanente y estable desde cinco años antes de la muerte del causante. Los nietos y sobrinos siempre que reúnan los requisitos establecidos en el párrafo anterior se considerarán con derecho cuando sus progenitores hayan fallecido, o cuando éstos vivos no tengan derecho a la tierra”.

Como puede visualizarse en la letra del precepto legal citado, se trata de una relación bastante exigua de familiares consanguíneos que pueden ser llamados a heredar la tierra y demás bienes agropecuarios, excluyéndose a parientes de fuerte relación afectiva en el medio rural. De lo anterior, pueden derivarse múltiples observaciones: es bien conocido que en las zonas rurales resultaba frecuente, hasta hace poco tiempo, que los padres no reconocieran legalmente a los hijos e hijas y que estos tampoco establecieran oportunamente su filiación, ni realizaran los procedimientos legales establecidos para corregir los errores frecuentes que pudieran aparecer en las certificaciones de nacimiento y defunción en cuanto a los datos acreditativos de su identidad, lo que constituye un reflejo de la ya aludida concepción particular que sobre la familia tiene el campesino.

12. El Decreto-Ley número 63 "Sobre la herencia de la tierra propiedad de agricultores pequeños" de fecha 30 de diciembre de 1982 y la Resolución Número 324 de 2 de noviembre de 1983 del Ministerio de la Agricultura, que constituyó el Reglamento del mismo. Dichas normas establecían que los herederos de un agricultor pequeño que no trabajasen personalmente la tierra, quedaban excluidos de la herencia de la misma y en consecuencia no tenían derecho a recibir compensación o pago alguno por ella. Dicha norma preceptuaba además que los herederos legítimos con derecho a la propiedad sobre la tierra, tenían que estar declarados judicialmente, además de haberla trabajado de forma estable y permanente desde un año antes del fallecimiento del causante. 
$\mathrm{Al}$ respecto también resulta forzoso tomar en consideración las serias dificultades que obstaculizan para el afectado obtener sentencia favorable de los tribunales cuando se debe acudir a ellos para la subsanación de errores en las certificaciones del registro civil en cuanto a nombres y fecha de nacimiento, o para que se declare que una persona que es conocida por un nombre o sobrenombre (cuestión muy común en el medio rural), tiene otro nombre en realidad, por sólo poner algunos ejemplos; es por ello que buscar una solución más cercana a la noción de familia que existe en el medio rural siguiendo los principios y fines del Derecho Agrario, resultaría mucho más factible que apegarse a la fórmula muchas veces rígida presentada por el Derecho Civil.

En este sentido también vale la pena considerar que "la existencia de problemas demográficos como el éxodo rural, acumulado durante décadas que se manifiesta como causa y a la vez efecto del desempeño desfavorable del sector agropecuario y del déficit en el desarrollo rural, se ha asociado al de la deficiente composición estructural por edades y por sexos en el medio rural"13.

La lectura del ya citado artículo 18 del Decreto Ley 125, refiere una relación bastante reducida de los parientes a los que se les concede el derecho a la herencia de la tierra y demás bienes agropecuarios, quedando excluidos otros como los primos y tíos, y en el caso de los nietos y sobrinos se les exigen requisitos adicionales, por los cuales pueden quedar finalmente excluidos. Tampoco se prevé una solución favorable en cuanto a concederles derecho a los parientes por afinidad, como a los hijastros, yernos y otros, aún y cuando muchas veces en casos concretos estas personas son las que en justicia más lo merecen, porque llevan más tiempo de trabajo en la finca y pudieran resultar los herederos más idóneos para garantizar la continuidad y sostenibilidad del desarrollo de la agricultura en forma familiar. En su articulado se norma la tierra como bien heredable sólo por aquellos parientes del agricultor pequeño fallecido que la hayan trabajado de forma permanente y estable desde 5 años anteriores a su muerte, en proporciones iguales, sus hijos, padres, hermanos y el cónyuge sobreviviente y los nietos y sobrinos en el caso de que sus padres estén fallecidos o de estar estos vivos, no tengan derecho a la tierra.

La normativa en cuestión establece además en su artículo 20 el derecho al cobro del precio de la tierra y demás bienes agropecuarios del causante para aquellos herederos que no han trabajado la tierra de forma permanente y estable, careciendo de ingresos particulares y mostrando una dependencia económica del agricultor pequeño ${ }^{14}$. Asimismo, en el artículo siguiente, señala algunos parientes que

13. F. Pérez Cabrera, “¿Y quién trabaja en el campo?”, Granma, 4 de abril (2008): 7.

14. Artículo 20.- Tendrán derecho al cobro del precio de la tierra, y de los bienes agropecuarios, las personas a que se refiere el Artículo 18 que no estuvieran trabajando la tierra en el momento del fallecimiento del agricultor pequeño, cuando carezcan de ingresos propios y hayan tenido dependencia económica desde cinco años antes de dicho fallecimiento del agricultor pequeño, y hayan mantenido dicha dependencia hasta la fecha de la adjudicación, comprendiéndose en estos casos los siguientes:

a) el cónyuge sobreviviente;

b) los padres, las hijas o las hermanas del causante;

c) los impedidos temporalmente para trabajar la tierra por causa ajena a su voluntad, siempre que antes del impedimento lo hayan hecho por un término no inferior de cinco años;

ch) los que por causas físicas o mentales estén totalmente impedidos para el trabajo; y

d) los que hayan arribado o no a la edad laboral legalmente establecida, dentro del término de cinco años anteriores al fallecimiento del causante. 
aún disponiendo de ingresos propios y no estando dedicados al trabajo de la tierra en el momento del fallecimiento del agricultor pequeño, por encontrarse en situaciones especiales, tienen derecho al cobro del precio de la tierra y de los bienes agropecuarios ${ }^{15}$.

En el caso de aquellos que sólo reciben el precio de la tierra y demás bienes agropecuarios, el Ministerio de la Agricultura dispone el traspaso de los mismos a favor del Estado en la proporción que corresponda, pero si estas personas demuestran que pueden incorporarse a trabajar la tierra personalmente dentro de un término prudencial, el Ministerio de la Agricultura, oído el parecer de la ANAP (Asociación Nacional de Agricultores Pequeños) y el MINAZ (Ministerio del Azúcar) cuando proceda, podrá disponer que se les adjudique la tierra y los bienes agropecuarios. La propiedad personal de los agricultores pequeños se transmite por la legislación sucesoria común señalada en el Código Civil vigente en Cuba, lo que prueba el carácter supletorio del mismo en materia agraria ${ }^{16}$.

Se estableció además que las transmisiones de tierras realizadas en vida antes del 24 de febrero de 1976 por propietarios actualmente fallecidos, a favor de algunas de las personas nombradas en el artículo 18 de este Decreto Ley, tendrán derecho para solicitar la adjudicación de la tierra que ocupen, siempre que hayan trabajado permanentemente y de forma estable en esa tierra. Para el caso de las propiedades de los agricultores pequeños fallecidos antes del 24 de febrero de 1976, el trabajo en esas tierras se exigirá que haya sido realizado en forma permanente y estable desde antes de la promulgación de la Constitución de la República ${ }^{17}$ y no desde cinco años antes del fallecimiento del causante. Cuando no existan personas con derecho a la adjudicación de la tierra y bienes agropecuarios de un agricultor pequeño fallecido o al cobro de su precio, éstos pasaran a propiedad estatal no como heredero, sino por el ius imperii concedido a éste.

15. Artículo 21.- Igual derecho que el referido en el Artículo anterior tendrán los que, aún disponiendo de ingresos económicos y no estando dedicados al trabajo de la tierra en el momento del fallecimiento del agricultor pequeño, estén en alguna de las situaciones siguientes:

a) cumpliendo el Servicio Militar General o misiones internacionalistas, siempre que antes de su incorporación a esas tareas hayan trabajado la tierra y la suma del tiempo trabajado, y el del que se encuentre prestando el servicio o la misión, sea no menor de cinco años;

b) teniendo edad laboral estén cursando estudios en la educación general, politécnica y laboral, o en la educación técnica y profesional, dentro de los límites de edad establecidos; y

c) habiendo egresado de centros superiores estén cumpliendo el servicio social.

16. Artículo 23.- En los casos señalados en los artículos 20, 21 y 22, el Ministerio de la Agricultura dispondrá el traspaso de la tierra y demás bienes agropecuarios al Estado, en la proporción que corresponda. No obstante, cuando las personas referidas en los artículos 20 y 21 demostraran que podrían incorporarse a trabajar la tierra personalmente dentro de un término prudencial, el Ministro de la Agricultura, oído el parecer de la Asociación Nacional de Agricultores Pequeños, y del Ministerio del Azúcar cuando proceda, podrá disponer que se les adjudiquen la tierra y los bienes agropecuarios.

Artículo 24.- Los demás bienes no relacionados con la explotación de la tierra se transmitirán de acuerdo con la legislación civil común

17. Referida a la Constitución de la República de Cuba promulgada en 24 de febrero de 1976, derogada recientemente por la Constitución de 10 de abril de 2019. 
Otro aspecto interesante radica en el término como habíamos visto, de cinco años de trabajo permanente y estable, lo cual también puede tener una interpretación errada, según lo dispuesto en el propio Decreto Ley al señalar, que se entiende por trabajo permanente y estable en la tierra, como el trabajo personal que se realice habitualmente y en forma continuada según los requerimientos de la producción agropecuaria a la que esté destinada la tierra, y cualquier otro relacionado con la atención a la misma que resulte necesario; excluyéndose generalmente, a los familiares que tienen otro vínculo laboral y en cuanto a los ingresos propios, los no provenientes de la explotación de la tierra, cuya cuantía sea superior al mínimo establecido a la pensión otorgada a los agricultores pequeños por la venta de su tierra; y la dependencia económica, la situación del que careciendo de ingresos propios, su subsistencia proceda de la producción de la tierra.

No existe respecto a la propiedad del agricultor pequeño la posibilidad de su transmisión por vía testamentaria, señalándolo así el artículo 29 del citado Decreto Ley y el Acuerdo número 34 de 1986 del Tribunal Supremo Popular. Se expresa también que aquel que por causas ajenas a su voluntad dejara de trabajar temporalmente la tierra sobre la cual tenga derechos, le haya sido o no adjudicada, podrá mantener el derecho a su propiedad sin trabajarla por el término de un año, contado a partir de la fecha en que dejara de hacerlo, transcurrido el cual, se podrá proceder a su adquisición por el Estado mediante compra, incluidos los bienes agropecuarios, o cuando corresponda, el inicio del proceso de expropiación forzosa conforme a lo establecido en la legislación vigente y en el artículo 10, siempre que no existan familiares que debidamente autorizados por el MINAG (Ministerio de la Agricultura) pudieran garantizar su atención.

Además en el artículo 32 del citado Decreto - Ley, establece que dicho organismo, oído el parecer del Presidente de la ANAP y del MINAZ cuando proceda, podrá resolver que a una persona que no haya reunido todos los requisitos establecidos para la adjudicación de una tierra, le sean reconocidos todos los derechos para la adjudicación de esta forma de propiedad, lo que constituyó una innovación; pero este artículo al no señalar concretamente lo que quiso decir el legislador, cae en el plano de la subjetividad de quienes lo aplicarán. "Que no reúnan todos los requisitos" puede entenderse de muchas formas, primero debemos valorar el relativo al parentesco, teniendo en cuenta específicamente a los parientes señalados, el segundo requisito fundamental, está dado por el trabajo permanente y estable; y el tercero por la dependencia económica. Pudiéramos interpretar esto, diciendo que no reúnan los requisitos puede referirse también a tener el tiempo de trabajo y no de parentesco o tener la dependencia económica y no el parentesco. Sin embargo, la interpretación que se ha dado en la Dirección Jurídica del MINAG es sólo al que le falte el tiempo de trabajo de cinco años o la dependencia económica durante igual tiempo, pero siempre teniendo el vínculo de parentesco, aunque existen varias resoluciones ministeriales, que le conceden la propiedad a los que no teniendo el vínculo de parentesco, tienen el tiempo de trabajo, dándoseles derecho a solicitar el usufructo de la misma.

Establece además la normativa en análisis, la posibilidad de que la adjudicación no se realice en igual proporción, constituyendo una innovación, pues permite que cada heredero constituya o se con- 
vierta en un propietario independiente, al establecer la posibilidad de adjudicarse en correspondencia con la forma en que se haya explotado la unidad de producción, en una participación no proporcional con el resto de los herederos. Si bien es justo que la tierra es, según uno de los principios del Derecho Agrario Cubano, para quien la trabaja, con esta forma de adjudicación, se está legalizando post morten, una posible ilegalidad conformada en vida del agricultor pequeño al parcelarla, cosa que está prohibido. No debe confundirse, la forma en que se ha decidido explotar la unidad de producción con ayuda familiar en vida de su propietario, lo cual no implica que sea necesario adjudicarla en proporciones distintas, a la muerte del agricultor pequeño.

En las entrevistas realizadas a los especialistas en cuanto a las deficiencias que presenta el Decreto-Ley se obtuvieron los siguientes resultados: el 98\% de los entrevistados coinciden en la necesidad de modificar el artículo 18 en cuanto a la inclusión de las personas con derecho a la herencia de la tierra, no contempladas actualmente por no presentar los vínculos de parentesco, y el $2 \%$ no están de acuerdo con que se incluyan, pues para ellos sería injusto con los herederos legales del agricultor pequeño.

El 100\% de los entrevistados coincide en la imperiosa necesidad de la puesta en vigor de un nuevo Decreto-Ley referido al Régimen de Transmisión y Herencia de la Tierra que incluya todos los supuestos para la tramitación intervivos y mortis causa de los bienes agrarios del agricultor pequeño, sin hacer referencia a la herencia testamentaria en materia agraria.

El 95\% de los entrevistados concuerda que la modificación del artículo 32 del actual Decreto Ley 125/91 constituye una novedosa propuesta sobre la base de garantizar y potenciar las relaciones jurídicas agropecuarias actualmente en Cuba, mientras que el 5\% plantea que dado el carácter autónomo del Derecho Agrario es necesario definir los requisitos y las personas a las que se hace alusión en el artículo 32 de la mencionada norma.

Los argumentos expuestos anteriormente, expresan las principales insuficiencias que contempla el Decreto-Ley No.125/91 demostrando realmente las necesarias e inminentes modificaciones a esta norma, a fin de lograr una mejor contextualización y cumplimiento normativo, sin dar paso a incorrectas interpretaciones y aplicaciones subjetivas.

De ahí que a criterio de las autoras, resulta prudente modificar los artículos 18 y 32 del Decreto Ley 125 de 30 de enero de 1991, sobre la propiedad, posesión y herencia de la tierra y demás bienes agropecuarios, de forma tal que incluya a la familia ensamblada en el orden sucesorio agrario cubano, por lo que constituye propuesta de la presente investigación la siguiente redacción de los artículos 18 y 32 de la SECCION TERCERA sobre la Transmisión de Tierra y Bienes Agropecuarios o su Precio, por fallecimiento de un Agricultor Pequeño: 


\section{ARTÍCULO 18:}

- Tendrán derecho a heredar la tierra y bienes agropecuarios que hayan sido propiedad y estado en posesión de un agricultor pequeño fallecido, y a su adjudicación en proporciones iguales, sus hijos, padres, hermanos y el cónyuge sobreviviente.

- Los nietos, sobrinos que se considerarán con derecho cuando sus progenitores hayan fallecido, o cuando estos vivos no tengan derecho a la tierra.

- Otras personas que por afinidad, afecto, amor, y propósitos comunes decidan unirse al núcleo familiar del agricultor pequeño para formar parte de este cuyas relaciones se desarrollan en el ámbito rural y agropecuario y se encuentren trabajando la tierra con anterioridad al fallecimiento del agricultor pequeño.

- No obstante, lo señalado en los párrafos anteriores, el Ministerio de la Agricultura podrá disponer que la adjudicación no se realice en igual proporción, sino en correspondencia con la forma en que se haya explotado la unidad de producción.

\section{ARTÍCULO 32:}

- El Ministro de la Agricultura, oído el parecer del Presidente de la Asociación Nacional de Agricultores Pequeños y del AZCUBA cuando proceda, podrá resolver que a una persona que no haya reunido todos los requisitos establecidos para la adjudicación de la tierra, excepto la de haberla trabajado en forma permanente y estable desde cinco ańos antes de la muerte del causante, le sean reconocidos los derechos sobre ésta.

Como se ha podido apreciar, el derecho agrario en materia sucesoria ha quedado rezagado respecto a los nuevos modelos familiares que se visualizan hoy en la sociedad, resultando necesario atemperar la normativa vigente a la realidad socio-familiar imperante.

\section{CONCLUSIONES}

Primera: A través de la historia el Derecho Sucesorio Agrario ha evolucionado constantemente hasta la actualidad sobre la base del desarrollo y estudios jurídicos doctrinales de las instituciones que lo componen, dentro de ellas la familia juega un papel preponderante como célula fundamental de la sociedad, y como en los últimos tiempos el término se ha diversificado tanto, el Derecho Agrario no ha quedado al margen de ello. Tal es el caso de la familia ensamblada o reconstituida definida como aquel grupo de personas que sin tener vínculos consanguíneos establecen relaciones de afinidad donde prima el amor, respeto y unión de una verdadera familia, lo que se extiende al ámbito rural y agropecuario. 
Segunda: El Decreto-Ley Número 125 de 1991 "Régimen Jurídico de la Propiedad de los Pequeños Agricultores en Cuba", se aparta normativamente del proceso sucesorio civil común, quedando determinado por un marco especial, autónomo, amplio, diverso y bastante disperso, evidenciándose la necesidad de incluir a la familia ensamblada dentro del llamado a suceder regulado en dicha norma sustantiva agraria, teniendo en cuenta la propuesta de modificación ofrecida en esta investigación, propiciando así con ello las garantías jurídicas que no ofrece el orden sucesorio agrario actual.

\section{REFERENCIAS}

- Castro Morales, Y. “Las Nuevas construcciones familiares, desafío para el derecho”. Granma, 7 de junio de 2016, 3. Acceso el 19 de diciembre de 2018 desde: http://www.granma.cu/cuba/2016-06-07/las-nuevas-construcciones-familiares-desafiopara-el-derecho-i-07-06-2016-23-06-06

- Constitución de la República de Cuba de 1976, con las reformas de 1992, en Gaceta Oficial de la República de Cuba, Extraordinaria, No. 7, de 1 de agosto de 1992.

- Decreto Ley 63/1982, Sobre la herencia de la tierra propiedad de Agricultores Pequeños. GOE (1982).

- Decreto Ley 125/91, Régimen de posesión, propiedad y herencia de la tierra y bienes agropecuarios.

- $\quad$ Decreto No. 566 de 17 de mayo de 1907 (Orden Militar No.62).

- El feudalismo en la Edad Media. La Sociedad Feudal, origen y características. Acceso el 12 de enero (2018) desde, www.portalplanetasedna.com.ar/feudalismo.htm

- Espocendra Amor, M.E. "Las relaciones de parentesco como forma de vínculo social". Tesis de Doctorado en Ciencias Sociológicas. Universidad de La Habana, Cuba, 2000.

- Figueras, José Julián. “La Transmisión de la Tierra en Cuba”. Tesis de Especialidad en Asesoría Jurídica. Universidad de Oriente, Santiago de Cuba, Cuba, 2006. Acceso el 7 de enero de 2018 desde: www.eumed.net/librosgratis/2012b/1213/implementacion_tribunales_agrarios.html

- Guillén Catalán, R. y Vega Cardona, R. J. (Ed.). Cuestiones Jurídicas de la empresa Familiar en España y en Cuba. Navarra, España: Aranzadi, SA, 2016.

- Hinojos Villalobos, Luis Agustín. "La concubina ante la sucesión legítima agraria”, Estudios Agrarios, (s.f): 104-115, acceso el 25 de octubre (2019), www.pa.gob.mx.publica.pdf 
- $\quad$ Las sucesiones. Acceso el 20 de noviembre de 2018 desde: www.cronotecagenealogica.com/lassucesiones.html

- Ley No. 59/1987 de 16 de julio, anotado y concordado con los ordenamientos cubano y español, por Ángel Acedo Penco y Leonardo B. Pérez Gallardo, Dykinson, Madrid.

- McCormack Bécquer, Maritza. Temas de Derecho Agrario Cubano. La Habana, Cuba: Félix Varela, 2007.

- Pavó Acosta, Rolando. La Justicia Agraria y sus Desafios. La Habana, Cuba: Unijuris, 2012.

- Pérez Cabrera, F. “¡Y quién trabaja en el campo?” Granma, 4 de abril (2008).

- Resolución No. 324 de 2 de noviembre de 1983, del Ministerio de la Agricultura, -Reglamento del Decreto-Ley No. 63. Acceso el 29 de mayo de 2018 desde: http://www.revista.anap.cu/?age_id

- Resolución No. 24 de 19 de marzo de 1991 del Ministerio de la Agricultura, Reglamento del Decreto-Ley No. 125. Acceso el 29 de mayo de 2018 desde, http://www.revista.anap.cu/?page_id=1149

- Resolución No. 170 de 19 de marzo de 1991, del Ministerio de la Agricultura, GOC No.20 (2017).

- Záes Nieto. B.C, Derecho Agrario. La sucesión agraria en Panamá, 2013, acceso el 15 de noviembre de 2018, estufamil.blogspot.com/2013/06/sucesion-agraria-n-ombre.html

RECIBIDO: 26/11/2019

APROBADO: $15 / 04 / 2020$ 